\title{
Pengembangan Background Subtraction Menggunakan FCM Untuk Deteksi Objek Bergerak Berdasarkan Pencahayaan Yang Bervariasi
}

\author{
Development of Background Substraction Using FCM for Detection of Moving Objects \\ Based on Varied Lighting
}

\author{
Rama Aria Megantara ${ }^{1}$, Ricardus Anggi Pramunendar ${ }^{2}$ \\ ${ }^{1,2}$ Teknik Informatika, Fakultas Ilmu Komputer, Universitas Dian Nuswantoro \\ Jl. Imam Bonjol No. 207, Semarang, 50131, Telp. (024) 3517261 \\ Email : ${ }^{1 * a r i a @ d s n . d i n u s . a c . i d, ~}{ }^{2}$ ricardus.anggi@dsn.dinus.ac.id
}

\begin{abstract}
Abstrak
Pendataan dari video yang direkam pada waktu malam hari memiliki tingkat kesulitan yang lebih tinggi daripada waktu pagi atau siang hari. Perubahan pencahayaan yang dihasilkan dapat mempengaruhi kualitas gambar dari rekaman video yang dihasilkan. Sehingga pengaruh pencahayaan pada saat malam hari menghasilkan kualitas rekaman video yang sangat rendah, hal ini disebabkan karena pencahayaan pada malam hari sering mengalami perubahan secara drastis. Beberapa metode yang sering digunakan dalam menyelesaikan masalah pelacakan objek bergerak antara lain background subtraction dan algoritma OTSU. Dalam menentukan threshold, algoritma OTSU tidak dapat mendeteksi gambar secara optimal saat berhubungan dengan gambar lain dilevel abu-abu. Dengan mengusulkan algoritma adaptive threshold yang didapatkan dari algoritma FCM diharapkan dapat meningkatkan akurasi untuk mendeteksi objek bergerak pada pencahayaan yang bervarisi. Sehingga dapat dilakukan penelitian ke depan untuk analisis cerdas dalam melacak pola dan deteksi perilaku anomali oleh kendaraan di jalan
\end{abstract}

Kata kunci--video, background subtraction, algoritma OTSU, adaptive threshold, FCM (Fuzzy C-Means). morning or afternoon. The resulting illumination changes can affect the image quality of the resulting video footage. So that the effect of lighting on at night to produce quality video recording is very low, this is because the lighting at night often experience drastic changes. Several methods are commonly used in solving the problem of tracking moving objects include background subtraction and Otsu algorithm. In determining the threshold, Otsu algorithm can not detect images optimally when associated with another image at the level of gray. With the proposed adaptive threshold algorithm obtained from the FCM algorithm is expected to improve the accuracy of detecting moving objects on varied lighting. So that research can be carried forward for intelligent analysis of the trace patterns and behavioral anomaly detection by a vehicle on the road.

Keywords--video, background subtraction, algoritma OTSU, adaptive threshold, FCM (Fuzzy C-Means)

\section{PENDAHULUAN}

Munculnya komputer berkecepatan tinggi dan kamera tingkat beresolution tinggi telah memperbaharui minat penelitian dalam bidang visi computer dan telah diterapkan di berbagai macam aplikasi seperti dalam bidang keamanan, militer, dan olahraga [1]. Dalam aplikasi tersebut, salah satu tugas yang paling sering dilakukan adalah menentukan jumlah, posisi, dan 
pergerakan berbagai objek. Analisa dari hasil deteksi pergerakan atau pelacakan yang didapatkan dapat digunakan untuk tujuan pengawasan otomatis secara visual seperti pengawasan lalulintas kendaraan dan aktivitas manusia[2], [3]. Hal tersebut menawarkan kontek untuk ekstraksi informasi penting seperti gerak adegan dan statistik lalu lintas, klasifikasi objek, identifikasi manusia, deteksi anomali, serta analisis interaksi antara kendaraan, antara manusia, atau antara kendaraan dan manusia [4].

Meskipun terdapat banyak metode untuk melakukan pelacakan yang efektif telah diusulkan [2]. Namun, pelacakan objek bergerak dari frame ke frame di urutan video yang ditangkap oleh kamera masih terdapat banyak kesulitan dalam merancang sebuah algoritma pelacakan yang akurat dan ini merupakan tugas yang sangat menantang [5]-[7]. Tantangan datang dari [8] perubahan pencahayaan yang signifikan, posisi yang bervasiari dari object, dan deformasi non-linear bentuk object, noise yang didapatkan dalam pengambilan data dan latar belakang yang sangat bervasiasi, dll.

Perubahan cahaya yang signifikan tersebut sering terjadi pada video yang direkam pada waktu malam hari. Video rekaman tersebut memiliki tingkat kesulitan yang lebih tinggi daripada waktu pagi atau siang hari. Perubahan pencahayaan yang dihasilkan dapat mempengaruhi kualitas gambar dari rekaman video yang dihasilkan. Sehingga pengaruh pencahayaan pada saat malam hari menghasilkan kualitas rekaman video yang sangat rendah, hal ini disebabkan karena pencahayaan pada malam hari sering mengalami perubahan secara drastic [9]. Pada penelitian Wang [9] juga disampaikan bahwa sebuah alat pengawasan otomatis didepan pintu masuk lift pada malam hari mendapatkan cahaya yang terpancar dari dalam lift dan ketika lift terbuka dapat berubah dari semula cahaya terpancar tinggi menjadi sangat rendah karena pengaruh keadaan lingkungan.

Beberapa metode yang sering digunakan dalam menyelesaikan masalah pelacakan objek bergerak antara lain background subtraction [2], [10]. Menganalisa urutan video yang berguna untuk mengekstrak foreground dan background gambar dengan memodelkan latar belakang dari gambar video, hal ini merupakan proses utama yang dilakukan dalam metode ini. Dengan memisahkan foreground dan background tersebut diperlukan sebuah nilai threshold yang sesuai [11]. Menurut [2], algoritma OTSU merupakan algoritma paling klasik yang digunakan untuk melakukan segmentasi pada gambar. Dalam menentukan threshold, algoritma OTSU tidak dapat mendeteksi gambar secara optimal saat berhubungan dengan gambar lain dilevel abu-abu.

\section{METODE PENELITIAN}

Berdasarkan latar belakang yang telah ditentukan diatas, dapat dirumuskan bahwa:

1 Pengumpulan data

Pengumpulan data merupakan tahap awal dari penelitian. Dalam tahap ini ditentukan jenis dan sumber data yang akurat. Sumber data pada penelitian ini adalah data berupa video pada malam hari kira-kira pada pukul 17.00-19.00 menggunakan jenis kamera handycam. Kamera handycam diletakkan pada posisi yg stabil mengarah ke objek kemudian data yang didapat bisa dianalisa.

2 Pengolahan awal data

Pada dasarnya video merupakan kumpulan dari suatu image sequences, oleh karena itu hal pertama yang dilakukan mengubah atau mengextract data video menjadi satu image, kemudian image tersebut akan diproses dan dianalisa. 


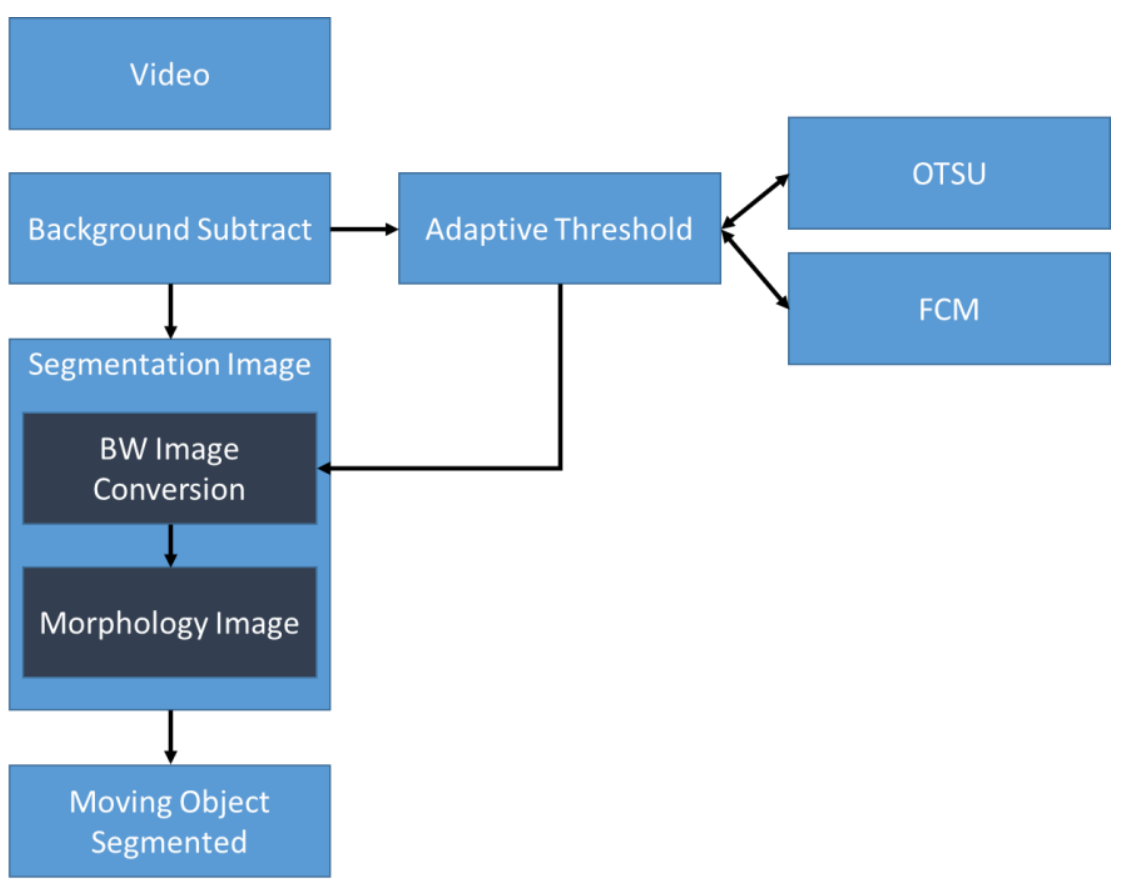

Gambar 1 Metode yang diusulkan

\subsection{OTSU}

Metode OTSU metode memilih batas ambang (threshold) secara otomatis dari tingkat keabu-abuan histogram melalui analisis diskriminan. Analisis diskriminan tersebut diharapkan dapat memaksimalkan pemisahan objek (foreground) dan latar belakang (background). Metode OTSU dimulai dengan normalisasi histogram citra sebagai fungsi probability discrete density sebagai:

$$
p_{r}\left(r_{q}\right)=\frac{n_{q}}{n}, \operatorname{dimana} q=0,1,2, \ldots, L-1
$$

Dimana $\mathrm{n}$ adalah total jumlah pixel dalam citra, $\mathrm{n}_{\mathrm{q}}$ adalah jumlah pixel $\mathrm{r}_{\mathrm{q}}$, dan $\mathrm{L}$ adalah total jumlah level intensitas citra. Dalam menentukan nilai T dengan memaksimalkan between class variance yang didevinisikan sebagai berikut:

$$
\sigma_{B}^{2}=\omega_{o}\left(\mu_{0}-\mu_{T}\right)^{2}+\omega_{1}\left(\mu_{1}-\mu_{T}\right)^{2}
$$

Dimana didapatkan dari:

$$
\begin{gathered}
\omega_{o}=\sum_{q=0}^{k-1} p_{q}\left(r_{q}\right) \text { sedangkan } \omega_{1}=\sum_{q=k}^{L-1} p_{q}\left(r_{q}\right) \\
\mu_{0}=\sum_{q=0}^{k-1} \frac{q p_{q}\left(r_{q}\right)}{\omega_{o}} \text { sedangkan } \mu_{1}=\sum_{q=k}^{L-1} \frac{q p_{q}\left(r_{q}\right)}{\omega_{o}} \\
\mu_{T}=\sum_{q=0}^{L-1} q p_{q}\left(r_{q}\right)
\end{gathered}
$$

\subsection{Fuzzy C-Means Algorithm}


FCM menghasilkan matrixs yang berisi kepemilikan dari beberapa objek di tiap cluster. Untuk strategi pemilihan threshold menggunakan FCM. Threshold adalah nilai rata-rata dari maximum pada objek dengan pusat terkecil dan minimum dengan pusat tengah.

$$
S S E=\sum_{i=1}^{N} \sum_{j=1}^{C} u_{i j}^{m}\left\|x_{i}-c_{j}\right\|^{2}, \quad 1 \leq m \leq \infty
$$

Dimana untuk rumus diatas memperlihatkan kepemilikan setiap pixel di dalam cluster:

$$
\begin{gathered}
\sum_{i=1}^{c} u_{i j}=1,1 \leq j \leq n \\
u_{i j} \geq 0,1 \leq i \leq c, 1 \leq j \leq n \\
\sum_{i=1}^{n} u_{i j}=1, \quad 1 \leq i \leq c
\end{gathered}
$$

Dalam algoritma FCM terdiri dari beberapa langkah berikut:

$>$ Mencari input data di dalam gambar

$>$ Memilih nomor dari cluster dan nilainya

$>$ Menghitung pembagian matrik menggunakan

$$
u_{i j}=1 / \sum_{j=1}^{c}\left(\frac{d_{i k}}{d_{j k}}\right)^{\frac{2}{m-1}}
$$

Mengubah cluster yang ditengah dnegan cluster yang baru:

$$
c_{j}=\frac{\sum_{k=1}^{n} u_{i k}^{m} x_{k}}{\sum_{k=1}^{n} u_{i k}^{m}}
$$

Pada penelitian ini FCM digunakan untuk memberi batas antara pixel sebagai foreground dan background prosesnya menggunakan background subtraction akhirnya Morphology digunakan untuk mendapatkan objek yang bagus dalam pendeteksian.

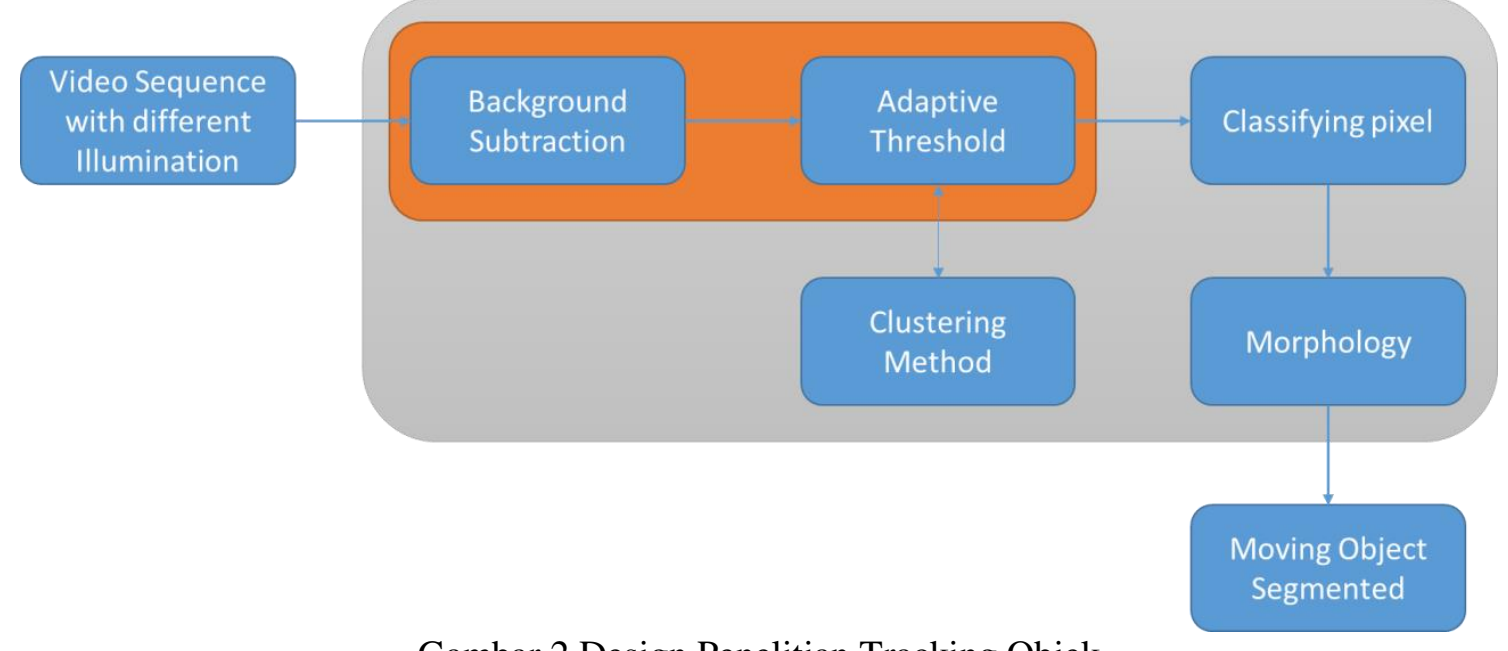

Gambar 2 Design Penelitian Tracking Objek 
4 Eksperimen dan pengetesan metode

Pada tahap ini, dijelaskan tentang teknik pengujian yang digunakan. Mengambil beberapa gambar untuk dibandingkan. Lalu dilakukan proses komparasi menggunakan MSE dan PSNR.

5 Evaluasi Hasil

Pada tahap ini dibahas tentang hasil evaluasi dari eksperimen yang telah dilakukan. Pengukuran dengan menggunakan MSE dan PSNR untuk mengetahui akurasi masingmasing.

\section{HASIL DAN PEMBAHASAN}

Algoritma ini diuji dalam beberapa sekuens video yang berbeda. Yaitu menggunakan objek berupa mobil bergerak dari atas menuju ke bawah pada petang hari antara jam 17.00 WIB hingga jam 19.00 WIB. Video yang lainnya diambil dari kegiatan orang berjalan diwaktu yang sama. Pada bagian ini menunjukkan hasil akhir dari proses pelacakan dari urutan video yang disertai dengan error disaat algoritma mendeteksi objek tersebut. Error didapatkan dari perbandingan hasil deteksi secara manual dengan hasil deteksi yang dilakukan oleh algoritma dalam proses mendapatkan hasil pelacakan yang akurat.

Gambar dibawah menunjukkan hasil output dari pertama urutan video di mana kendaraan bergerak dari atas menuju ke bawah pada petang hari antara jam 17.00 WIB hingga jam 19.00 WIB. Perpindahan objek terdeteksi dan kotak batas diberikan sekitar kendaraan yang bergerak.
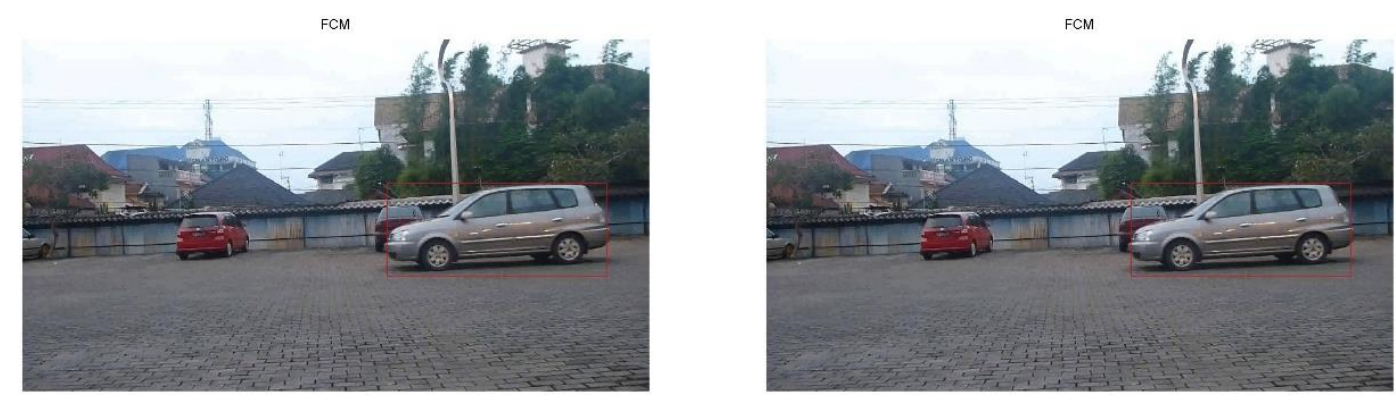

Gambar 3 Output Akhir bergerak deteksi objek dari urutan video

\subsection{Hasil dari Background Substraction}

Background substracktion bertujuan untuk menghapus background gambar sehingga foreground dapat terlihat dengan jelas tanpa adanya background yang beraneka ragam. Dalam penelitian ini, hasil background substraction diperlihatkan di gambar 4.2. Terdiri dari gambar a yang didapatkan dari pengurangan antara gambar no 1 dengan gambar no 2, gambar b, c dan d merupakan gambar no 101, 201, dan 301. Yang didapatkan dari pengurangan antara nomor gambar tersebut dengan gambar ke $\mathrm{t}+1$. Berikut adalah hasil dari metode background substraction: 

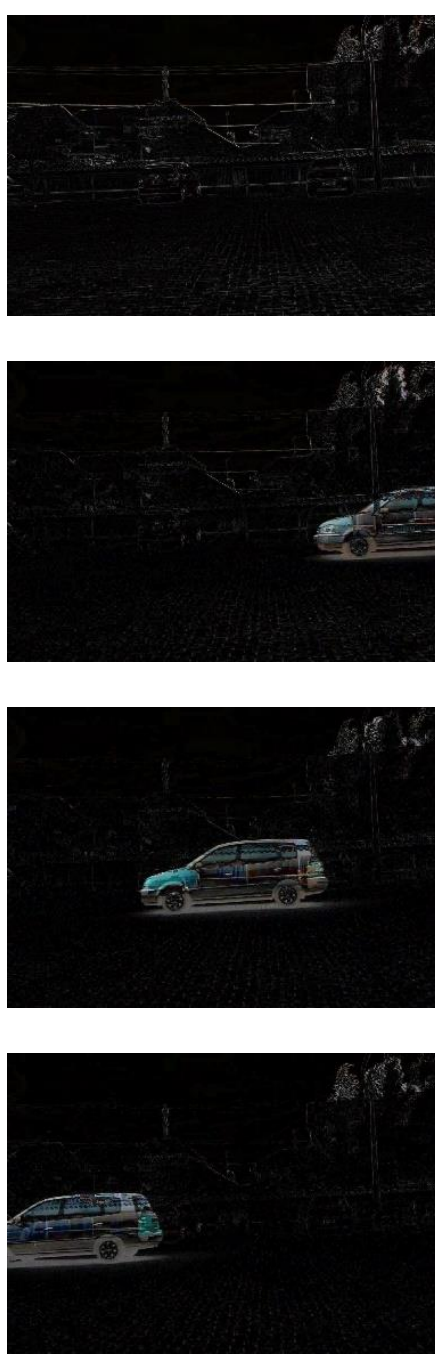
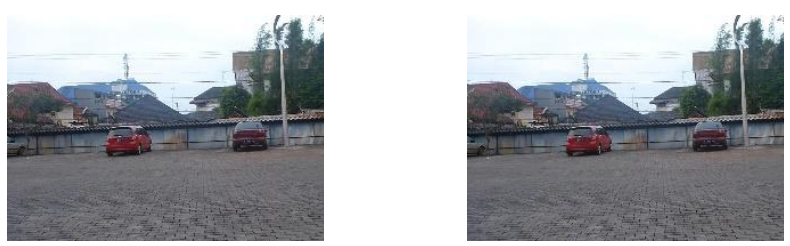

(a)
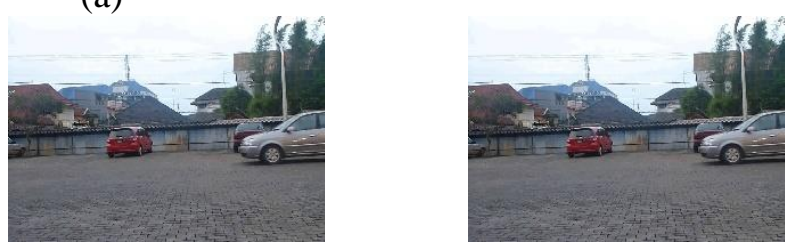

(b)
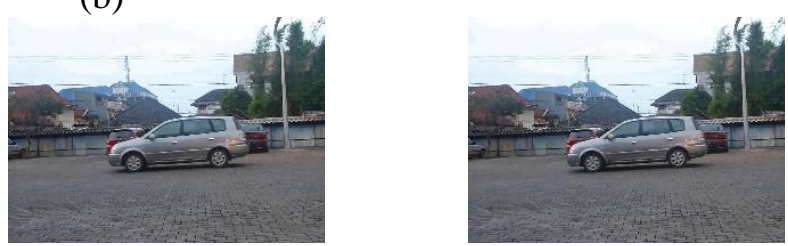

(c)
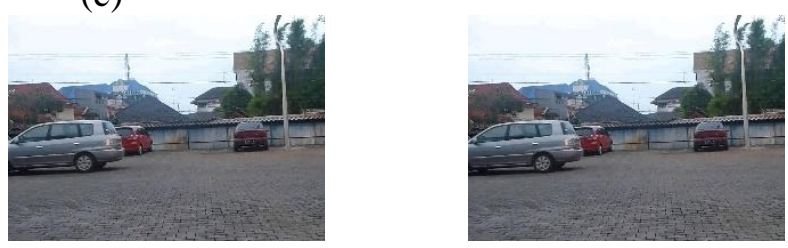

(d)

Gambar 4 Output Akhir bergerak deteksi objek dari urutan video

3.2 Hasil Perbandingan metode FCM dan OTSU pada siang hari

Pada penelitian ini dilakukan pengujian berdasarkan perbandingan hasil MSE dari metode FCM dan OTSU, hasil MSE yang di dapatkan pada kondisi Siang hari ditunjukkan pada tabel berikut ini:

Tabel 1 Hasil MSE metode FCM dan OTSU

\begin{tabular}{|c|c|c|}
\hline No Frame & FCM & OTSU \\
\hline 1 & 0.034573 & 0.090531 \\
\hline 101 & 0.022943 & 0.019065 \\
\hline 201 & 0.035989 & 0.045123 \\
\hline 301 & 0.042039 & 0.042900 \\
\hline
\end{tabular}


Pada penelitian ini dilakukan pengujian berdasarkan perbandingan hasil PSNR dari metode FCM dan OTSU, hasil PSNR yang di dapatkan pada kondisi Siang hari ditunjukkan pada tabel berikut ini:

Tabel 2 Hasil PSNR metode FCM dan OTSU

\begin{tabular}{|c|c|c|}
\hline No Frame & FCM & OTSU \\
\hline 1 & 62.7435 & 58.5628 \\
\hline 101 & 64.5244 & 65.3285 \\
\hline 201 & 62.5691 & 61.5869 \\
\hline 301 & 61.8943 & 61.8063 \\
\hline
\end{tabular}

3.3 Hasil Perbandingan pada metode FCM dan OTSU antara pukul 18.00 hingga 19.00

Penggunaan metode FCM dan OTSU pada penelitian ini diterapkan untuk data pada kondisi pencahayaan antara pukul 18.00 hingga 19.00. Hasil menunjukan kelebihan dan kekurangan setiap metode dibandingkan dengan hasil pelacakan secara manual. Berikut merupakan beberapa hasil perbedaan yang didapatkan dari FCM dan OTSU:

Tabel 3 Perbandingan Hasil Threshold FCM dan OTSU

\begin{tabular}{|l|l|l|l|l|l|l|l|l|}
\hline No & FCM & OTSU & No & FCM & OTSU & No & FCM & OTSU \\
\hline 1 & 0.005013 & 0.027451 & 101 & 0.019598 & 0.031373 & 201 & 0.003865 & 0.031373 \\
\hline 6 & 0.004823 & 0.023529 & 106 & 0.018741 & 0.031373 & 206 & 0.003776 & 0.027451 \\
\hline 11 & 0.004365 & 0.023529 & 111 & 0.014437 & 0.027451 & 211 & 0.003578 & 0.027451 \\
\hline 16 & 0.004197 & 0.023529 & 116 & 0.020576 & 0.031373 & 216 & 0.003422 & 0.023529 \\
\hline 21 & 0.003813 & 0.023529 & 121 & 0.016633 & 0.031373 & 221 & 0.003396 & 0.023529 \\
\hline 26 & 0.003592 & 0.027451 & 126 & 0.015255 & 0.027451 & 226 & 0.003404 & 0.023529 \\
\hline 31 & 0.003333 & 0.027451 & 131 & 0.013915 & 0.027451 & 231 & 0.003437 & 0.023529 \\
\hline 36 & 0.002999 & 0.027451 & 136 & 0.014001 & 0.027451 & 236 & 0.00348 & 0.027451 \\
\hline 41 & 0.003065 & 0.031373 & 141 & 0.012704 & 0.027451 & 241 & 0.003523 & 0.027451 \\
\hline 46 & 0.002948 & 0.031373 & 146 & 0.013735 & 0.027451 & 246 & 0.003481 & 0.023529 \\
\hline 51 & 0.002772 & 0.098039 & 151 & 0.013554 & 0.027451 & 251 & 0.003606 & 0.027451 \\
\hline 56 & 0.002546 & 0.084314 & 156 & 0.013884 & 0.027451 & 256 & 0.003604 & 0.027451 \\
\hline 61 & 0.00081 & 0.031373 & 161 & 0.008599 & 0.027451 & 261 & 0.00357 & 0.023529 \\
\hline 66 & 0.003072 & 0.092157 & 166 & 0.010994 & 0.031373 & 266 & 0.003607 & 0.023529 \\
\hline 71 & 0.000383 & 0.090196 & 171 & 0.012641 & 0.027451 & 271 & 0.003603 & 0.027451 \\
\hline 76 & 0.00276 & 0.035294 & 176 & 0.005507 & 0.031373 & 276 & 0.003558 & 0.023529 \\
\hline 81 & 0.023023 & 0.101961 & 181 & 0.004772 & 0.031373 & 281 & 0.003588 & 0.023529 \\
\hline
\end{tabular}




\begin{tabular}{|l|l|l|l|l|l|l|l|l|}
\hline 86 & 0.020985 & 0.062745 & 186 & 0.004567 & 0.027451 & 511 & 0.00523 & 0.023529 \\
\hline 91 & 0.011439 & 0.062745 & 191 & 0.004527 & 0.031373 & 516 & 0.004579 & 0.023529 \\
\hline 96 & 0.015577 & 0.058824 & 196 & 0.004121 & 0.027451 & 521 & 0.004094 & 0.023529 \\
\hline
\end{tabular}

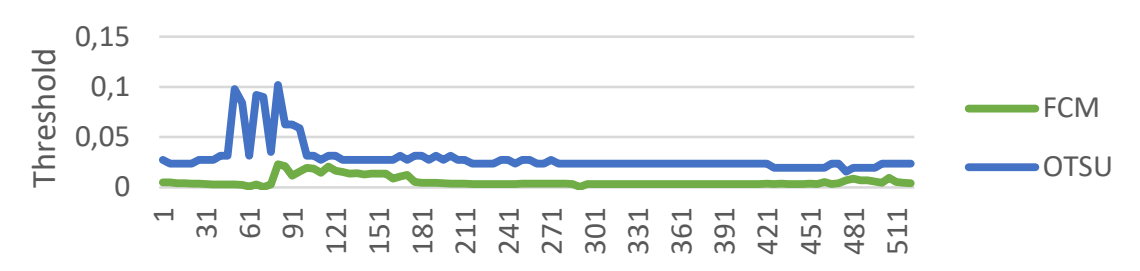

Gambar 5 Threshold Histogram FCM dan OTSU

\section{KESIMPULAN}

Hasil dari eksperimen penelitian mengenai deteksi objek bregerak berdasarkan pencahayaan yang bervariasi maka dapat di simpulkan sebagai berikut :

a. Deteksi Objek Bergerak didalam pencahayaan bervariasi menggunakan algoritma FCM karena Algoritma cluster yang tidak menggunakan pengawasan telah berhasil diterapkan pada beberapa masalah di pixel adalah FCM (Fuzzy C-Means).

b. Pada Penelitian ini akan difokuskan pada Deteksi Objek Bergerak Pada Pencahayaan yang Bervariasi setelah melakukan hasil perbandingan MSE dan PSNR menggunakan Algoritma FCM ditemukan lebih sedikit error,sehingga menggunakan Algoritma FCM lebih bisa mendeteksi objek bergerak pada pencahayaan yang bervariasi.

\section{DAFTAR PUSTAKA}

[1] M. Toumi, A. Maizate, M. Ouzzif, and M. Said Salah, "Dynamic Clustering Algorithm for Tracking Targets with High and Variable Celerity (ATHVC)," J. Comput. Networks Commun., vol. 2016, pp. 1-10, 2016.

[2] M. A. Soeleman, M. Hariadi, and M. H. Purnomo, "Adaptive threshold for background subtraction in moving object detection using Fuzzy C-Means clustering," in TENCON 2012 IEEE Region 10 Conference, 2012, pp. 1-5.

[3] R. S. Basuki, M. A. Soeleman, R. A. Pramunendar, A. F. Yogananti, and C. Supriyanto, "Video Object Segmentation Applying Spectral," J. Theor. Appl. Inf. Technol., vol. 72, no. 2, pp. 208-214, 2015.

[4] N. Suzuki, K. Hirasawa, K. Tanaka, Y. Kobayashi, Y. Sato, and Y. Fujino, "Learning motion patterns and anomaly detection by Human trajectory analysis," 2007 IEEE Int. Conf. Syst. Man Cybern., pp. 498-503, 2007.

[5] W. Abd-Almageed, M. Hussein, M. Abdelkader, and L. S. Davis, "Real-Time Human Detection and Tracking from Mobile Vehicles," in 2007 IEEE Intelligent Transportation Systems Conference, 2007, pp. 149-154.

[6] K. R. Reddy, K. H. Priya, and N. Neelima, "Object Detection and Tracking -- A Survey," in 2015 International Conference on Computational Intelligence and Communication Networks (CICN), 2015, pp. 418-421.

[7] D. Walther, D. R. Edgington, and C. Koch, "Detection and tracking of objects in 
underwater video," Proc. 2004 IEEE Comput. Soc. Conf. Comput. Vis. Pattern Recognition, 2004. CVPR 2004., vol. 1, pp. 0-5, 2004.

[8] Meng-Che Chuang, Jenq-Neng Hwang, K. Williams, and R. Towler, "Tracking Live Fish From Low-Contrast and Low-Frame-Rate Stereo Videos," IEEE Trans. Circuits Syst. Video Technol., vol. 25, no. 1, pp. 167-179, Jan. 2015.

[9] Y. K. Wang and C. T. Fan, "Moving object detection for night surveillance," Proc. 2010 6th Int. Conf. Intell. Inf. Hiding Multimed. Signal Process. IIHMSP 2010, pp. 236239, 2010.

[10] V. Mahadevan and N. Vasconcelos, "Background subtraction in highly dynamic scenes," in 2008 IEEE Conference on Computer Vision and Pattern Recognition, 2008, pp. 1-6.

[11] R. S. Basuki, M. Hariadi, and R. A. Pramunendar, "Fuzzy C-Means Algorithm for Adaptive Threshold on Alpha Matting," in Citee, 2012, no. July, pp. 177-180. 